\title{
A Multi-layered Analysis of The New York Times Op-Ed: A Case Study
}

\begin{abstract}
By Nashwa Elyamany*
Newspaper Opposite-Editorial articles (Op-Eds) represent an important form of intellectual debate that communicate views on issues of public policy and help shape public opinion. They are challenging, information rich, and persuasive short media texts imbued with worldviews, arguments, sarcasms, and biases, hence provide saliency cues regarding key national and international affairs. Recent police killings of citizens in the US have attracted massive coverage in the media, predominantly in the Op-Ed section of The New York Times in 2015. Instances of killing unarmed African Americans have come to the forefront of the discussion on race and race relations. Informed by Critical Discourse Analysis, this case study is a multilayered qualitative analysis of the Baltimore unrest media coverage, particularly in one article authored by a guest contributor in The New York Times. To identify how the case of the Baltimore unrest is rhetorically represented in media discourse, the study is premised on an eclectic approach drawing on Appraisal Theory, Conceptual Metaphor Theory, and Systemic Functional Grammar. The paper aims to: first, pinpoint the inherent appraisal resources used by Connolly to frame his argument and dialogically position the intended audiences in (dis)alignment with his worldviews; second, showcase the metaphoric repertoire that serves his ideological stance; third, highlight the overall transitivity profile that frames his argument of the Baltimore unrest. Despite the fact that emotional, ethical, and logical appeals are invested on, the writer makes calculated choices, leaning the most on the last two to promote, persuade, and strengthen his arguments, on the one hand, and to align the intended readers with the ideologically laden messages therein, on the other.
\end{abstract}

Keywords: appraisal, conceptual metaphor, opposite-editorial, transitivity.

\section{Introduction}

"Living in a society that constantly marginalizes you, invalidates your experiences and emotions, and fosters insecurity, it becomes an uphill battle to love yourself. Based on the messages that we receive from all corners of society (from politics to economics, from media to schools), we are taught to hate ourselves. To affirm, value, and validate yourself-to love yourself - amidst this daily onslaught of disparaging messages is not only political but also radical. It is radical because you're not supposed to survive". (Pate, 2014)

High-profile police brutality is arguably the most divisive national issue and alarming flashpoint in race relations in the US (Klinger, 2012). Police excessive use of force continues to proliferate and is once again in the national and international spotlight in the wake of several recent controversial fatal shootings of citizens, notably in 2014. The US began to experience a crisis of police legitimacy as a natural consequence of these events (Cook, 2015; Mellman, 2015; Nix \& Pickett, 2017; Wolfe \& Nix, 2016). The acts of violence

\footnotetext{
${ }^{*}$ Head of Languages Department, Arab Academy for Science, Technology and Maritime Transport (AASTMT), Egypt.
} 
against black people have spurred nationwide furor over the implicit racial bias, prompting politicians, journalists, and scholars alike to question the nexus of race, criminal justice, and police militarization. A large body of literature sheds light on the causes of police killings and consistently demonstrates that the fatal brutality correlates with violent crime rates, income inequality, and racial heterogeneity (Bielejewski, 2016; Legewie \& Fagan, 2016).

Minority communities are deeply affected by the publicized examples of police violence (Weitzer, 2015), not excluding Baltimore. Notorious for the high violent crime levels, Baltimore is the largest city in Maryland. Over the years, severe tension grew on account of the high levels of poverty, racial segregation, and zero-tolerance policies that prevailed the city, targeting African American civilians in epidemic proportions, who were, compared to other racial groups, systematically preyed upon. During the Baltimore unrest in 2014, the police were facing a challenging period of turmoil as incidents of police use of force against minorities continued to draw national attention. Anecdotally, sensational videos documenting some of these incidents have gone viral, generating significant media attention, fueling intense scrutiny and public discontent with the police (Weitzer, 2015). In doing so, police misconduct has experienced an unprecedented new visibility (Victor \& McPhate, 2016).

One remarkable incident was on April 12, 2015 when the police arrested Freddie Gray, a young Black man, for allegedly possessing an illegal switchblade knife. Footage of the arrest showed Freddie Gray being dragged to a police van seeming limp and screaming in pain (Stolberg \& Babcock, 2015). On April 18, protests broke out outside the Baltimore Police Department in the Western district as the young man remained in a coma. When Freddie Gray died on the following day, because of a spinal cord injury, the city seemed to reach a tipping point and outburst in civil unrest (Kindy, Lowery, Rich, Tate, \& Jenkins, 2016). Protests galvanized throughout the city after Gray's death and peaked with riot and violence. Days of protests and rioting resulted in millions of dollars' worth of looting, property damage, and destruction within the city (Wegner, 2015). Mainstream media turned their lens to America's many disadvantaged minorities, largely due to the instigation of the massive coverage that sparked civil unrest in several American cities (Culhane, Boman, \& Schweitzer, 2016; Pyrooz, Decker, Wolfe, \& Shjarback, 2016; Williams, Bowman, \& Jung, 2016).

More specifically, the killings of black citizens in Baltimore have garnered attention and massive coverage in the Opposite-Editorial article (henceforth OpEd) of The New York Times, particularly in 2015. The Op-Ed debuted in The New York Times on September 21, 1970, and since its inception, it is written by a diverse array of elite experts on the salient issues of the day with the purpose of prompting civic discourse and shaping public opinion (Golan, 2010, 2013). Strategically located in most daily newspapers in the time being, the Op-Ed is a rather short, in-depth reflection meant to bridge readership and feature several critical lenses on complex realities. Ideally speaking, it is a rich terrain consecrated to solicit a broad range of voices and accommodate opinions of those not affiliated to the newspapers on issues of public interest to enhance readers' ability of making informed decisions and opinions. 
Over the past few decades, Op-Ed writing has taken on prominence and evolved into an art of its own; the Op-Ed pages of The New York Times are no exception. Op-Eds have become challenging, information rich, and persuasive media texts vested with worldviews, arguments, sarcasms, and biases, hence provide saliency cues regarding national pressing issues. It becomes, therefore, germane to critically examine the rhetorical strategies and ideologies infused within and unravel how Op-Ed authors provide readers with (un)balanced exposure of competing issue stands, with the ultimate aim of uncovering the larger ideologically (un)biased discourses therein. As van Dijk (1993, p. 241) posits, elite discourses (political, racial, educational, and academic) find expression through the mediating and reinforcing functions of the media, and, accordingly, provide the dominant worldview and control public opinion. Since language is instrumental to the institutionalization of (a)symmetries and dominance, it can also be used to subvert them. Van Dijk (1991, 2000, 2006, 2015) argues that the dominant textual representations in journalistic discourse have the potential to position readers and naturalize particular underlying ideologies by which social actors are judged. With this line of thought in mind, Op-Ed articles, being explicitly subjective, value laden, and evaluative, represent an important form of intellectual debate whereby readers are positioned to regard some of the social actors in a more positive light and others in a more negative light.

\section{Literature Review}

A substantial body of research on journalistic discourse, particularly editorials and opinion pieces, is discernible in the literature to date (see, for example, Ansary \& Babaii, 2005; Bolivar, 1994; García Orosa, López García, \& Gallur Santorum, 2013; Healy, 2011; Jegede, 2015; Lawal, 2015; Le, 2002a, 2002b, 2002c, 2003, 2004, 2006, 2007, 2010; Lee \& Lin, 2006; van Dijk, 1992, 1998; Vestergaard, 2000a, 2000b; Wang, 2007; Zarza \& Tan, 2016). Several models of analysis have been developed for the analysis of editorials, namely: Flower's (1991) that focuses attention on the discourse participants and the linguistic strategies of beliefs and values; van Dijk's (1998) socio-cognitive approach that places emphasis on the production and interpretation of texts; and Lihua's (2009) that incorporates evaluation in the analysis of the editorial discourse. A consistent pattern in terms of the rhetorical organization and stylistic strategies of these genres (to frame particular ideologies, advance specific propositions, and shape public opinions) is well documented in prior scholarship. Whereas some studies dwell upon the use of evaluative language in editorials (Blanco, 2011; Morley, 2009; Plungian, 2001), other studies are geared toward the use and form of storytelling techniques in news texts (Wahl-Jorgensen, 2013a, 2013b; Van Krieken, Sanders, \& Hoeken, 2016) and the effects of such techniques on the engagement levels with news texts (Shen, Ahern, \& Baker, 2014; Van Krieken, Sanders, \& Hoeken, 2015).

Seemingly sublimated to the editorial page, the Op-Ed dialogue is essentially one that is among readers, experts, and freelancers, unfettered by the newspaper's 
official editorial positions (Salisbury, 1988, p. 317). Despite the importance of the Op-Ed genre as a journalistic forum that communicates views on issues of public policy, overtly evaluate events, and persuade readers, hence help shape public opinion, the extant scant research is geared solely toward Op-Ed's use of issue-framing (see, for example, Golan, 2010, 2013; Porpora \& Nikolaev, 2008) and not from critical discourse analysis (CDA) perspectives. Van Dijk (1996, 2000) reiterates that newspaper opinion discourses, including commentaries, play an important role in the formation and shifting of public opinion, in setting the political agenda, and in influencing social debate, decision making and other forms of social and political action. Therefore, when examining media discourse surrounding racial issues in Op-Eds, it is imperative to analyze media representations of police violence incidents from appraisal, cognitive, and systemic functional vantage points.

Objectivity in reporting incidents in newspapers is a long-standing myth (White, 2006) heavily invested on in studies premised on the various traditions of CDA (see, for example, Bendarek, 2006; Van Dijk, 1985, 1988, 2006, 2015; Fairclough, 2013). These scholars are highly influential in advancing the view that a dialectic relationship exists between the linguistic features of texts and the institutions, social practices, and social conditions in which the texts are embedded. The role of sources in the news has certainly received some attention in the linguistic journalistic literature (Sundar, 1998; Manning, 2001). However, little attention is paid to the evaluative role sources play in the content of the Op-Ed pages whereby external voices are allowed to speak their minds much more loudly than authors do. In view of the hermeneutic nature of discourse analysis (Macken-Horarik 2003; Wodak \& Meyer 2001), it is acknowledged that in certain instances the same locutions can be interpreted differently depending on the reading position adopted (in support of, or as opposed to, the propositions made). Depending on the type and stance of the newspaper, these opinions may vary considerably in their ideological presuppositions. Do gatekeepers of newspapers select Op-Ed guest contributions that tacitly encode and reinforce the paper's worldview in alignment with its editorial orientation? Alternatively, do the Op-Eds of guest contributors act as a medium for the articulation of divergent opinions absent of institutional policy? This is an issue worthy of inspection from a CDA perspective, especially in argumentation primarily driven by evaluation in journalistic discourse.

On a different note, Conceptual Metaphor Theory (CMT) resolves the incongruities of linguistic metaphors by establishing a similarity between two apparently dissimilar entities (Lakoff \& Johnson, 2003). In (mediated) political media discourse, metaphor goes beyond being merely a cognitive phenomenon to being a strategic rhetorical resource for winning consensus and projecting certain truths and ideologies. In fact, metaphor has the power to transform complex political realities into more readily graspable concepts (Bougher, 2012); it may further be employed manipulatively to serve political agendas (e.g., arouse people's emotions, or privilege/rationalize particular accounts of social reality). Since CDA is geared towards the deconstruction of ideologically (un)biased discourses, metaphor appears to be among the covert linguistic tools 
that may mask subtle (a)symmetries and repressions. In a similar vein, the representations of experiential meanings in Op-Eds are always social and cultural constructs realized by the grammatical system of transitivity (Halliday \& Matthiessen, 2014). In the selective representation of states of being, actions, events, and situations, transitivity choices signal bias, manipulation, and ideology in media discourse. The choices a writer makes, accordingly, are ideologically significant. Van Dijk (2015) corroborates how possible manifest and latent meanings of individual texts relate to patterns of textual features and the socio-cultural and institutional context of their production and consumption.

In light of the aforementioned account, the current study aims to contribute to the Op-Ed scholarship by analyzing the source and content diversity strategies of an African American male guest contributor's Op-Ed article in The New York Times. This is in thorough examination of how evaluative stance and authorial/non-authorial voices are enacted in journalistic discourse from appraisal, cognitive and systemic functional vantage points.

\section{Research Questions}

The overarching research questions of the study are:

1. What are the inherent appraisal resources that shape the argument of Connolly's Op-Ed article in dialogic positioning of the intended audiences to be supportive of, or otherwise opposed to, the argument made?

2. What is the metaphoric repertoire that serves Connolly's ideological stance in the Op-Ed article under study?

3. What is transitivity profile of the Op-Ed article that helps galvanize Connolly's argument on the Baltimore unrest?

\section{Case Study}

A random selection of one Op-Ed article from the online version of The New York Times thematizing key controversial issues regarding the Baltimore unrest, and published on May 1, 2015, represents the case study for analysis. The research endeavor follows the case study method (Perry, 2011) for the information rich, in-depth analysis it affords. The article is entitled "Black Culture Is Not the Problem", retrieved from https://www.nytimes.com. It is written by the guest contributor Nathan Connolly, an associate professor of history in Johns Hopkins University, who writes about "racism, capitalism, politics, and people's overlapping understandings of property rights and civil rights in the US and the wider Americas" (https://history.jhu.edu/directory/nat han-connolly/). Among the highest average circulation rates of national newspapers (as cited on www.auditedmedia.com), The New York Times is favored in the current study for the quality of coverage and the political leaning and ideological affiliation it celebrates. More specifically, during the Baltimore unrest, 
it has kept the audiences informed about the high-profile cases of unarmed African-American men allegedly killed by police officers, reporting the latest and most significant news about them.

\section{Methodology}

This case study is an exploratory, multi-layered qualitative analysis of how the nationwide case of police killings and the Baltimore unrest are covered in the media discourse of the Op-Ed article under study. The paper is premised on a hybridized approach that rests on a trio of analytical frameworks: Appraisal Theory, Conceptual Metaphor Theory, and the transitivity system that falls under Systemic Functional Grammar.

Martin and White's (2007) appraisal theory provides a fine-grained taxonomy of lexical realizations for the analysis of evaluation in language. The system of attitude constitutes the main resource for evaluating, adopting stances, constructing textual personas, and managing interpersonal positionings and relationships whereas the other two systems, graduation and engagement, are attendant systems that contribute to attitude and function simultaneously. The attitude system enables the author to foreground his subjective presence through the construal of three main semantic domains, namely, affect (emotional states), judgement (evaluation of people and their social behaviors), and appreciation (evaluation of entities, processes, and phenomena) in either explicit or implicit manners, positive or negative ways.

The engagement system is concerned with the linguistic resources the writer uses to adopt a particular stance (interpersonal positioning) toward the propositions/values they advance as well as the intended audience they address. This is materialized by acknowledging their voice and/or other prior voices to either expand or contract the dialogic space, thereby creating possibilities for the reader to comply with or resist the position(s) constructed by the text. The graduation system operates across two axes of scalability: force and focus. Critically, choices in graduations of attitude and engagement affect strength of feeling and level of commitment to value positions (they either "up-scale" or "down-scale" evaluations).

Conceptual Metaphor Theory (CMT), developed by Lakoff and Johnson (2003), argues that metaphor allows us to understand abstract areas of experience in terms of more concrete, embodied ones. In the simplest sense, within CMT metaphor is a cross-domain mapping between the source (abstract concept) and target (physical experience) domains. The concept that becomes understood is the TARGET domain. The other concept, which facilitates understanding or discussion of the target is the SOURCE domain. Conceptual Metaphors (CMs) are written in capital letters whereas the linguistic realizations of CMs are written in small letters.

Finally, transitivity is a choice between processes (realized by a verb), participants (nominal group of a clause, typically representing persons, things, or abstract entities), and attributes ascribed to them (which typically characterize, 
identify, or locate the participants), against background details concerning time, place, manner, etc. (circumstances) attendant to the process itself. Six process types are distinguished in the transitivity system of English, which represent human experience in terms of physical and physiological actions (material and behavioral), thinking and speaking actions (mental and verbal) and actions that signal the existence of something/someone and their identifying features (existential and relational). Each different process in the transitivity system requires different kinds of participants. Circumstances represent in which manner and under what conditions the process is realized.

\section{Analysis}

\section{Appraisal Analysis}

In light of the appraisal taxonomy, attending as it does to the very parameters of evaluation variability, a thorough account is detailed in the sub-sections below dwelling upon all levels of refinement across the three systems of attitude, engagement, and graduation.

Attitude. In negotiation of solidarity, which is a complex process, Connolly turns his Op-Ed page into a mixing bowl of explicit authorial/non-authorial attitudinal inscriptions and attitudinal invocations. While the former are locutions with consistent attitudinal value communicated via evaluative lexical items, the latter are triggered (or betokened) by means of various mechanisms of association and implication. To elaborate, the author's overt sympathetic attitude, basically of judgement and appreciation with lower occurrences of affect, is expressed through a wide range of grammatical structures and lexis (i.e. attitudinally laden adjectives, nouns, and verbs) such as "spurred on", "ostensibly", "stained", "apparent", "dispossessed", "empathy", and "assault", which are ascribed to several appraisers (social actors, including himself). From a different angle, with the help of lexical metaphors like "fighting a myth" the writer tokenizes some extended and concerted action, even though he refrains from overtly describing the action in these terms. There are no explicitly negative (or positive) terms in this utterance, yet, via implicature, it has the potential to activate negative judgement values by apparently neutral, ideational meanings, which nevertheless, depending upon the reader's social, cultural, and ideological position, are meant to evoke judgement responses.

Essentially, attitudinal evaluations and other potentially contentious meanings are largely confined to materials attributed to external voices. At the onset of his Op-Ed, Connolly lays out numerous affectual responses toward police brutality to express dissatisfaction, solicit sympathy, and share emotional responses to the Baltimore turmoil. The presence of negative evaluative polarities and semantic intensification related to gradable lexical items, articulated by multiple appraisers, is discernible in the article under study. The affects, of the realis type, infused in the article are fundamentally those of the reporter voice, primarily ascribed to the non-authorial voices embedded in the media text, to 
negotiate solidarity and invite readers to sympathize and empathize. No traces of authorial affectual responses or references to his own mental state can be detected in the article, though. Example instantiations of affects to cite are italicized and bolded in the utterances below:

- "Instead, we lionize [-affect: antipathy] people like Toya Graham",

- "A Department of Justice report spurred on [-affect: displeasure] explicitly racist policing...",

- "the mayor later expressed regret [-affect: unhappiness]", and

- "...most observers did not see an understandable social response [-affect: disinclination] to apparent state inaction".

It is noteworthy in this regard that reports of affectual responses frequently act as tokens of other types of attitude, specifically to invoke judgements of human behavior, as indicated in the examples above. Connolly does not assign major importance to affect in the article, and proceeds with clear negative judgments of the social sanction type against a few social actors with references to prior statements, incidents, and positions. The author's attitude toward the racial disparities sweeping America is expressed mostly through inscribed, negative instantiations of judgments within the sub-category of propriety in disapproval of the current situation in black America. All forms of criticism Connolly provides are limited in terms of the moral or legal assessments, which encompass evaluative resources for assessing human behavior by reference to a society's system of moral and legal norms. Propriety is expressed in the italicized and bolded phrases in the utterances that follow:

- "...they saw thugs...criminal and thugs [-judgement: social sanction: propriety]",

- "...they are also fighting myth about degenerate [-judgement: social sanction: propriety] black culture",

- "...Instead, we lionize [-judgement: social sanction: propriety] people like Toya Graham",

- "... a city and a country that still segregates people [-judgement: social sanction: propriety] along racial lines", and

- "... a political culture that has long bound black bodies [-judgement: social sanction: propriety] to questions of property".

As indicated above, propriety values concern the social sphere of rightversus-wrong or good-versus-evil behaviors, which most societies penalize via law enforcements. Moreover, attitudinal judgments of the political actors frequently include comments on their moral character with respect to their truthfulness and ethical norms of behavior. The negatively assessed examples are indicative. For instance, how the observers or the mayor himself perceives those killed black people (as thugs and criminals) is out of a dominant ideology about the black culture at large, on the one hand, and out of a desire for social acceptance by the obsolete system that binds them, on the other. 
The attitudinal arrangements in the Op-Ed under study further operate somewhat indirectly and potentially invoke negative judgements of those who might be deemed responsible for the killings of black people or their parlous circumstances. These negative judgements are in alignment with simultaneously validated and intensified sourcing of similar assessments (as eventually illustrated in the engagement section). The author shows readers that it is not about a white- or black-dominant city, it is a nationwide problem of police violations to constitutional rights, even in the black-dominant Baltimore. Police problems are merely a subset of a broader racist system and evidence of longstanding problems with police racism and excessive violence is emphasized.

Connolly further applies his perspective to a series of issues prevalent in black America as shown in the italicized and bolded instantiations of negative appreciation of the valuation type. In the context of this study, valuation concerns the non-aesthetic appraisal of the evaluated entities leaning the most on social worth, which are to some extent institutionalized. Example instantiations of valuation subsume:

- "...Commentators noted the absence of black representatives [-appreciation: valuation: discredit/lack of recognition] among Ferguson's elected officials and its police leadership",

- "Ferguson's mostly white City Council and its courts spurred on explicitly racist policing [-appreciation: valuation: harm] in part to harvest fines [-appreciation: valuation: harm] from black residents", and

- "Yet the city still has one of the most stained records of police brutality [-appreciation: valuation: harm] in recent years".

The examples above show that packaging events as entities and appreciating them in terms of valuation functions as a resource for contextualizing affect and judgement. Hence, readers are repositioned as the text unfolds to be more aligned, in terms of their moral and political response, to the rhetoric therein. Overall, the inscribed and invoked subjective attitudes co-articulate with the discursive construction of Connolly's ideological stance.

Engagement. Engagement characterizes how Connolly dialogically positions himself with respect to his audience and the propositions referenced in the article in alignment with the evaluative stance of the external voices. Assuming some readers may resist the positions advanced by the Op-Ed article, Connolly uses a dialogic weaving of different voices to naturalize a number of positions and negotiate solidarity with the readership in a time of social and civil unrest in the US. The point of departure here is the distinction between two dialogic orientations: monogloss (dialogic contraction) in the form of bare assertions and heterogloss (dialogic expansion) which signals an alternative position or source. More specifically, the author takes the liberty of alternating between two engagement choices; key to the choice is whether he construes the position of the text as given or at issue and up for debate. In analyzing engagement, the researcher is interested in the extent to which the author acknowledges these 
alternative voices and, if he does, the different ways in which he interacts with them. Moreover, distinguishing voices is relevant to the current study since it helps illustrate the degree to which authorial subjectivity, or objectivity, is present in the article examined.

Connolly allows inter-subjective positioning as early as the first lines of his Op-Ed, skillfully manipulating instantiations of diaglossia to expand, thereby creating possibilities for the reader(s) to comply with (or otherwise resist) the positions constructed by the text. In effect, the expansive dialogic resources used by the author either entertain (i.e. the writer is represented as the source of the propositions or values, thereby making space for alternative viewpoints) or attribute (i.e. the author presents propositions and values as arising from some external sources). Both entertaining and attributive options are dialogically expansive as they ground the propositions in the subjectivity of an individual, thereby opening the space for dialogic alternatives.

When attributing, Connolly presents his proposition as one in a range of possible positions and abstains from explicitly interfering with the propositions made. This tendency makes it difficult to distinguish between authorial and non-authorial evaluative stance since voices are blurred. While some of the linguistic instantiations of the reported materials clearly stood out as outright forms of appraisal, others evaluated more moderately. Connolly deftly dissociates himself from the stances advanced, employing:

- verbal process reporting verbs with illocutionary force coupled with ostensibly unbiased sources. Examples are: "commentators noted the absence of black representatives..."; "A Department of Justice report highlighted how Ferguson's mostly white City Council..."; "the footage affirms violence as the best way to get wayward black people under control"; and "the mayor expressed regret"),

- third-person mental process verbs as in "Baltimore Police Commissioner applauded...", "Lester Freamon understood that following the money took our eyes off the street and up the chain of real political power".

Fundamentally, attribution in reporter voice (rather than in correspondent and/or commentator voice) of the acknowledge type predominates as a form of impersonalization through which the authorial voice is backgrounded. No overt indication of where the authorial voice stands in relation to the attributed, unmarked, and neutral propositions can be detected. Despite variation in their evaluative intensity, almost all reported material are negatively evaluative, attributed to the external sources ofcommentators, experts, community leaders, eyewitnesses, among others. By virtue of cultural resonance, the intertextual positioning of these social actors and the exculpatory accounts of police violence recast police in antagonistic roles and resituate the civil unrest as foci of local political controversy.

The attribute choice, in heteroglossic terms, helps readers attend to the anticipatory aspects of the text, to the signals Connolly provides as to how he expects those he addresses to respond to the current propositions and the value 
positions he advances. Martin and White (2007) argue that these reported selections seem to warrant objectivity and grant the paper protection from gross partiality. It is observable how the reporting verbs used at different junctures in the Op-Ed surface in tandem with evidential standing whereby the social standing or authority of the source acts as a sign (a token) that the associated value position is well-founded, reasonable or otherwise credible. Negative assessment is evoked through these purely experiential factual material which, as a result, has the potential to trigger a negative reaction in the reader's mind via processes of attitudinal inference. The reader is positioned to view the propositions made as highly warrantable and is aligned to certain truths of the matter. Connolly is describing a state of affairs based in facts but these facts, through appraisal, are furnished with subjective evaluations imbued with ideology.

An inquiry into the legitimizing function of intertextual positioning is worth dwelling upon. The interweaving of voices is part of the writer's effort to construct images, mobilize meanings, and further the argumentation to a climax to bring it to a closure, thus projecting a compliant reader aligned with the authorial/nonauthorial voices. Legitimation is achieved through the cultivation of shared valuations of phenomena, incidents, and social actors. Because legitimatory force is contextually, culturally, and temporally bound, an element might be legitimating in one culture, but not in another; and the status of an element vis-à-vis legitimation will alter through time. It follows, alignment in this article does not necessarily mean real consensus; often it is a question of whose claims on the issues at hand are going to dominate. As a consequence, the boundary between knowledge and opinion in the description of social actors and actions is distorted. The critical question is then whether readers are able to separate facts from ideology in the course of the op-ed discourse or take these subjective colorations as simply objective descriptions of the way the world really is in the US.

The positioning of the reader to take a negative view of the police culture is further conditioned when the writer intervenes (i.e. when he entertains) in several intriguing ways by which authorial alignment with the reported value positions is signalled. In collegiality with the non-authorial voices infused in the media text, Connolly implicitly expresses the position he takes with regard to the attributed material through:

- judgements as in "Baltimore Police Commissioner applauded her, pleading with parents to..." whereby a positive judgement of the commissioner is invoked by reference to his actions;

- modal adjuncts as in "the footage certainly affirms..." whereby Connolly overtly declares his support of the reported proposition or point of view by passing positive judgement on the reliability of the source itself; and

- intensifications as in "harvest fines" and "swift responses" to amplify the focus of the utterances made.

These textual insertions show how the killings come amid public outrage over a series of deaths of unarmed black men at the hands of law enforcement 
agents and highlight the brutality of the police culture. More vividly, there are utterances where the Op-Ed author issues directives that urge, command, or recommend actions with regard to the issue at hand, albeit less liberally, making them sound like a natural outcome emerging from the incidents and references he endorses early on in the article. The challenge Connolly faces is to shape an argument that would build shared values, yield immediate actions and, therefore, Connolly leans the most on:

- bare assertions as illustrated in "The problem is not black culture. It is policy and politics, the very things that bind together the history of Ferguson and Baltimore and, for that matter, the rest of America" to project representations of reported incidents or beliefs as categorical truths or facts; and

- epistemic modal verbs as shown in "political leaders, black and otherwise, can help us all see..." to express ability and reveal relations of authority and/or power.

In total, the interplay of authorial and non-authorial voices invites critical interpretations of the focal incidents that occur amid the controversy of police legitimacy. The different voices, along with the mental images they generate in the minds of readers, cultivate a civil right frame that, to Connolly, should attain prominence in the wider cultural space.

Graduation. Within attitude, the author manipulates graduation to amplify his negative feelings and assessments to scale up the strength of his utterances, hence serving the argument made. Implicitly, however, the vocabulary of focus often serves to index attitude, especially in cases where attitude is not inscribed in the amplified item. Particularly noteworthy is the use of deftly employed intensifiers, attitudinal lexis, and linguistic metaphors that augment the force or the intensity and degree of the realities the author is negotiating to maintain solidarity with the readers.

Intensifiers are visible in several instances, namely "ostensibly" and "routinely". Attitudinal lexis includes adjectives such as those in "stained records", "degenerate black culture", "subsequent unrest", "unarmed AfricanAmericans", "rioting son", "perceptible white power structure", "broad black inferiority", "bright spot", "preemptive riot", "swift responses", "all-too-familiar template", and "willful destruction" and the reporting verbs used such as "affirms", "highlighted", and "noted". All linguistic metaphors function as a medium for arousing emotions as the basis of evaluation, thus persuasion. Several examples relating to various social actors and issues at stake are found, explicitly in "in the wake of the shooting", "fighting myth", "harvest fines", "lionize people", "looting erupted", "on the heels of any ghetto economy", and "starved for income" whereby Connolly is maximally committed to the value position being advanced.

Through force, evaluations are graded along a sliding scale of force or intensity in relation to intensification or quantification. When Connolly upscales the force of the meaning, it usually indicates that he is strongly 
invested in the proposition whereas whenever it is downscaled, or the volume is turned down, it indicates he is less invested and is distancing himself from the proposition (the latter being seldom an option in the Op-Ed under study). Instances of softening are used as hedging, mitigating, or conciliatory devices in attempt to negotiate solidarity with the readers whom the author anticipates may not share his point of view. They express an explicit assessment of the degree of intensity (e.g., "...and the relative confinement of black unrest to black communities during this week's riot...") as well as quantity with respect to amount (e.g., "Slavery was not so much a labor system as it was a property regime") and extent (e.g., "What we do not prosecute nearly well enough, however, is the daily assault on black people's lives").

In sum, graduation resources elucidate the fact that many of Connolly's projections of alignment are not feigned. There are so many good reasons for locals to be outraged. The latest shootings in a string of highly publicized white-on-black police shootings in the US leave little room for debate; it has called into question police treatment of black America. Time has come for a national reckoning on race and policing in America.

\section{Cognitive Analysis}

In probing of how meanings are mobilized from a cognitive perspective, this analysis illuminates the metaphoric repertoire of Connolly's Op-Ed, which relates to his stance and ideology, showing how metaphorical framing has the potential to compromise the quality of argumentation. In their mediation of the racial issue under scrutiny, several linguistic metaphors reveal Connolly's apparently inadvertent ideological stance toward police brutality and violence. To create a persuasive emotional argument, the author makes use of a vast array of linguistic metaphors (as detailed earlier in the graduation section).

On a related note, the most dominant conceptual metaphor emerging in the Op-Ed discourse, inscribed in part by the nominal group, is "THE UNITED STATES OF AMERICA IS ONE FAMILY". Deploying a metaphor with high public resonance is a useful rhetorical tool to advance contentious claims. In terms of this conceptual metaphor, Connolly's argument is situated in a larger context, an "all-inclusive" America. This metaphor serves as a tool for prescribing solutions for the unfolding of the Baltimore killings. The metaphor is linguistically realized via Connolly's effective use of "we", its object variant "us", and the possessive adjective "our(s)", inducing the readership to conceptualize group identity, solidarity, and a national collective. More precisely, "we" is used anaphorically to render the conceptual metaphor, foregrounding responsibility and agency and assuming national singularity and homogeneity thus creating a discourse of sameness especially when decisions are controversial as illustrated in:

- "Yet when black people of influence make these arguments, it prevents us from questioning Baltimore...", "Instead, we lionize people like the Baltimore mother who went upside the head of her rioting son", 
- "We forget, for instance, about how officials, in their fear of black youth, issued what witnesses...", and

- "We have a right to expect that our administrators will use the bully pulpit to speak about the policies, systems and structures over which they preside".

As shown in these utterances, "we" is significant; it puts all the social actors in the same boat (with the author included) in spite of the gross disparities that exist. "We" clearly presupposes the existence of a "they" and/or "you". Thus, by inclusion, it, at the same time, excludes and assumes a parallel "other" exists elsewhere. In Connolly's Op-Ed, "we" is brought to full political effects in several occurrences, simultaneously inclusive of solidarity and exclusive of rejection. There is a constant ambivalence and slippage between exclusive and inclusive "we", as a rhetorical device for both the formation of in and out groups and for making the border between the two less identifiable. The inclusive "we" involves the intended readers, which, in turn, helps the author emphasize particular linkages in the Baltimore unrest and mutes others, hence the metaphorical reasoning succeeds to advance dialogue with proponents (as well as opponents) and position readers to hold a similar view of the desired actions. All of these forces (guised by "we") once compounded, may increase young black civilians' capacity to trust police officers and optimize their ability to see themselves as fully respected and valued community citizens. To Connolly, despite the growing diversity of the US, "we" must find a way to live together as one human family.

In the Op-Ed examined, metaphors are strategically used to encode social meanings and cultural presuppositions, to assume consensus for the argument Connolly projects as truth. Not only do they complement the assertions made by the author but they help present a balanced content of the non-authorial voices integrated in the article as well.

\section{Transitivity Analysis}

Connolly's Op-Ed provides abundant examples of the ideological significance of transitivity. Transitivity choices unravel facets of the author's ideology and stance toward the prevalent situation in black America and foreground the measures that need to be taken for a better, shared world. The expression or obfuscation of agency is indicative of ideology, where participants who are agents in transitive constructions are afforded more power than participants who are agents of intransitive constructions. All citizens of America (signaled often times in the article through the inclusive "we") are agents of a greater number of transitive verbs. Although the different types of processes are selectively dealt with in this analysis, there seems to be a clear pattern that is worthy of inspection.

The majority of the processes are material and relational in type. Material process verbs of the transformative type relate to the appraisers mentioned in the article (be it citizens in general, officials, political leaders, or commentators) in the participant role of Actor (or social actors, so to speak). They are construed as initiators of action and hence as participants who, at least potentially, are responsible for the events that transpired. The Goal (i.e. actions) of officials, 
for example, imply that the US is not for black people. Examples to cite are italicized and bolded in "people routinely borrowed against other human beings. They took out mortgages on them". and "Ferguson's mostly white City Council and its courts spurred on explicitly racist policing, in part to harvest fines from black residents". The material process type is mandated to attract sympathy and foreground the fact that it is the very actions of the officials, leaders, and the public (of which they have full control) that shape the dominant ideology pertaining to black culture and would in turn help change that ideology for a better America.

The attitude expressed through negative judgements in the article can be related to the number of negative material processes infused in the media text. What is happening in Ferguson or Baltimore is about so many issues, namely the systemic racism and the militarization of police work. However, there is light at the end of the tunnel toward the end of the Op-Ed if officials change their course of actions as shown in "political leaders, black and otherwise, can help us all...they can better use the power they have to...by devising a fairer tax structure, by investing in public space, community policing, tenants' rights and a government jobs program, our leaders can find a way forward".

Relational processes of the identifying type, on the other hand, surface in different junctures in the media text either to describe the status of the black people in America as in "Slavery was not so much a labor system as it was a property regime" and "The problem is not black culture. It is policy and politics", or to pinpoint what Americans should do as one family for a better shared life as in "We have a right to expect that our administrators will use the bully pulpit to speak about the policies, systems and structures over which they preside". In effective operation of these relational process verbs of the intensive/possessive type, Connolly expresses appreciation with respect to the political situation at stake. Living in a society where different rules apply to different citizens can be maddening to those getting the shorter end of the stick. To Connolly, it is the brutality of the police culture and violation of civil rights not the black culture that is under question in the US.

Connolly further makes effective use of "circumstantial adjuncts" of different types: cause, time, contingency, location, place, manner, condition, as well as others falling into different places in the sentence (at the beginning, in the middle, or at the end of clauses). Several adverbial and prepositional phrases illuminate the circumstances associated with the range of processes used and the diverse discourse markers used orchestrate quite well in weaving the text together, producing a well-developed and structured argument, as well as sequencing the transitivity choices embarked on. Examples to cite are italicized and bolded in the utterances below:

- "By devising a fairer tax structure, by investing in public space, community policing, tenants' rights and a government jobs program, our leaders can find a way forward" (Manner); and

- "Back in the day, people routinely borrowed against other human beings" (Time). 
Indeed, the orchestration of these processes serves the author's stance and ideology. While using language as a tool for deconstructing hidden power relationships has real value when examining social problems, it is important to remember that there is a great deal of power in solidarity as well. When it comes to solving social problems, it is solidarity, or true alignment, that engenders the greatest and most enduring social change.

\section{Conclusion}

This case study examines how Connolly's appraisal, cognitive, and transitivity choices frame the Baltimore unrest in line with the values, concerns, and fears of readership in his article in The New York Times. The researcher provides a socio-critical interpretation of how the Op-Ed argument contributes to inflame racial passions, and, by funneling audience attention toward certain topics and/or by influencing public perceptions of the national issue, highlights new social dynamics. Connolly's ideologically charged journalistic contribution reveals his primary agenda of calling attention to the racial disparities that have been a part of the criminal justice system for decades in the US. The Op-Ed may be read as impartial while at the same time it may advance a particular (axiological) value position. To Connolly, when it comes to the perceptions of how race impacts policing, it is almost as if black and white Americans live in two different worlds. Ending police brutality will require a reconstruction of the American social system so that it can provide affirmative action and reparations for African Americans.

Aligned with prior studies on editorials and opinion articles, a consistent pattern of representation for rhetorical appeal, namely the effective employment of a source and content diversity strategy, is detected to provide readers with a balanced exposure and a forum for debate on the national issue. The author and other social actors involved in the media text are strikingly similar in the evaluative position they advance with respect to police brutality; they strongly position the reader to take a negative view of the police and to sympathize with the black citizens. Despite the fact that emotional, ethical, and logical appeals are invested on, the writer makes calculated choices, leaning the most on the last two to promote, persuade, and strengthen his arguments, on the one hand, and to align readers with the ideologically laden messages therein, on the other.

\section{Limitations of the Study and Future Research}

This research endeavour is not without limitations. The first limitation is the nature of the paper being a case study. Caution should be exercised since the findings cannot be generalized beyond the randomly selected article until further research is carried out on a more representative sample. Op-Ed writers may show divergent or convergent patterns of ideological stance across diverse corpora of newspapers, in dis(alignment) with their respective editorial policies 
and orientations. Future research projects can examine a diversity of Op-Eds from local and national newspapers written by a wider pool of male/female, black/white Americans of different academic/professional backgrounds of different political leanings.

The second limitation is the selection of The New York Times, a more liberal leaning newspaper, placing a great value on reports of social justice. The editorial policy or orientation of a news organization is an important filter through which the organization presents news reality. This filter is reinforced when ideologically sensitive issues are involved. The titles, affiliations, and contributions of syndicated columnists and freelancers may affect the manner in which issues of national concern are discussed and so are worthy of investigation on a more representative sample in future scholarship.

\section{References}

Ansary, H., \& Babaii, E. (2005). The Generic Integrity of Newspaper Editorials: A Systemic Functional Perspective. RELC Journal, 36, 271-295.

Bednarek, M. (2006). Evaluation in Media Discourse: Analysis of Newspaper Corpus. London and New York: Continuum.

Bielejewski, A. (2016). Gangbusters, mavericks, and the cop next door: dominant models of American policing in popular culture. Kriminologisches Journal, 48(2), 106-127.

Blanco, M. P. (2011). The language of evaluation in English and Spanish editorials: A corpus-based study. In S. Goźdź-Roszkowski (Eds.), Explorations across languages and corpora, pp. 207-225. Frankfurt am Main: Peter Lang.

Bolivar, A. (1994). The structure of newspaper editorials. In M. Coulthard (Eds.), Advances in written text analysis, pp. 276-294. London: Routledge.

Bougher, L. D. (2012). The case for metaphor in political reasoning and cognition. Political Psychology, 33(1), 145-163.

Cook, P. J. (2015). Will the current crisis in police legitimacy increase crime? Research offers a way forward. Psychological Science in the Public Interest, 16(3), 71-74.

Culhane, S. E., Boman, J. H., \& Schweitzer, K. (2016). Public perceptions of the justifiability of police shootings: The role of body cameras in a pre- and postFerguson experiment. Police Quarterly, 19(3), 251-274.

Fairclough, N. (2013). Critical Discourse Analysis: The Critical Study of Language. London: Routledge.

Flower, R. (1991). Language in the news. London: Routledge.

García Orosa, B., López García, X., \& Gallur Santorum, S. (2013). Analysis of the adaptation of the editorials of five newspapers from different European countries to the online environment. Revista Latina de Comunicación Social, 68, 485-500.

Golan, G. J. (2010). Editorials, Op-ed Columns Frame Medical Marijuana Debate. Newspaper Research Journal, 31(3), 50-61.

Golan, G. J. (2013). The Gates of Op-Ed Diplomacy: Newspaper Framing the 2011 Egyptian Revolution. International Communication Gazette, 75(4), 359-373.

Halliday, M. A. K., \& Matthiessen, C. M. I. M. (2014). An Introduction to Functional Grammar. London: Arnold. 
Healy, D. (2011). Ideologies and us versus them: A comparative study using systemic functional grammar of Irish and British editorials related to the ending of the IRA's armed campaign. PhD Thesis, University of Birmingham, Birmingham.

Jegede, O. O. (2015). Language and ideology in the media: A study of Nigerian newspaper editorials. International Journal of English, Literature and Culture, $3(3), 76-84$.

Kindy, K., Lowery, W., Rich, S., Tate, J., \& Jenkins, J. (2016). Fatal shootings by police are up in the first six months of 2016. Post analysis finds. The Washington Post.

Klinger, D. (2012). On the problems and promise of research on lethal police violence: A research note. Homicide Studies, 16(1), 78-96.

Lakoff, G., \& Johnson, M. (2003). Metaphors We Live By. Chicago: University of Chicago Press.

Lawal, O. A. (2015). Pragmatics of truth and modality in newspaper editorials: An example of the Punch and the Tribune. Theory and Practice in Language Studies, 5(4), 688-693.

Le, E. (2002a). Themes and Hierarchical Structure of Written Texts. In M. Louwerse, W. van Peer (Eds.), Thematics: Interdisciplinary Studies, pp. 171-187. Amsterdam, Philadelphia: John Benjamins.

Le, E. (2002b). The concept of Europe in Le Monde's editorials: Tensions in the construction of a European identity. Journal of Language and Politics, 1(2), 279-325.

Le, E. (2002c). Human rights discourse and international relations: Le Monde's editorials on Russia. Discourse \& Society, 13(3), 373-408.

Le, E. (2003). Information sources as a persuasive strategy in editorials: Le Monde and The New York Times. Written Communication, 20(4), 478-510.

Le, E. (2004). Active participation within written argumentation: metadiscourse and editorialist's authority. Journal of Pragmatics, 36(4), 687-714.

Le, E. (2006). The Spiral of "Anti-Other Rhetoric" - Discourses of Identity and the International Media Echo. Series: Discourse Approaches to Politics, Society and Culture. Amsterdam, Philadelphia: John Benjamins.

Le, E. (2007). Elites Dailies and Projections of Cultural Identities: A Comparison of Le Monde and The New York Times. In J. M. Bernardo Paniagua, G. Lopez Garcia, P. Sancho Cremades, E. Serra Alegre (Eds.), Critical Discourse Analysis of Media Texts, pp. 195-208. Valencia: Universitat de Valencia.

Le, E. (2010). Editorials and the power of media: Interweaving of socio-cultural identities. Amsterdam, The Netherlands: John Benjamins Publishing Co.

Lee, F. L. F., \& Lin, A. M. Y. (2006). Newspaper editorial discourse and the politics of self-censorship in Hong Kong. Discourse and Society, 17(2), 331-358.

Legewie, J., \& Fagan, J. (2016). Group threat, police officer diversity, and the deadly use of police force. Columbia Public Law Research Paper No. 14-512.

Lihua, L. (2009). Discourse construction of social power: Interpersonal rhetoric in editorials of the China Daily. Discourse Studies, 11(1), 59-78.

Macken-Horarik, M. (2003). Envoi: Intractable Issues in Appraisal Analysis? Text, 23(2), 313-319.

Manning, P. (2001). News and News Sources: A Critical Introduction. London: SAGE Publications.

Martin, J. R., \& White, P. R. R. (2007). Language of Evaluation: Appraisal in English. London: Palgrave Macmillan.

Mellman, M. (2015). The crisis of police legitimacy. The Hill. May 5.

Morley, J. (2009). Lexical cohesion and rhetorical structure. In J. Flowerdew, M. Mahlberg (Eds.), Lexical cohesion and corpus linguistics, pp. 5-22. Amsterdam: John Benjamins. 
Nix, J., \& Pickett, G. T. (2017). Third-person perceptions, hostile media effects, and policing: Developing a theoretical framework for assessing the Ferguson effect. Journal of Criminal Justice, 51, 24-33.

Pate, S. (2014). The radical politics of self-love and self-care. The feminist wire.

Perry, F. L. (2011). Research in Applied Linguistics: Becoming a Discerning Consumer (2nd ed.). New York, NY: Routledge Press.

Plungian, V. (2001). The place of evidentiality within the universal grammatical space. Journal of Pragmatics, 33, 349-357.

Porpora, D. V., \& Nikolaev, A. (2008). Moral Muting in US Newspaper Op-eds Debating the Attack on Iraq. Discourse and Communication, 2(2), 165-84.

Pyrooz, D. C., Decker, S. H., Wolfe, S. E., \& Shjarback, J. A. (2016). Was there a Ferguson Effect on crime rates in large US cities? Journal of Criminal Justice, $46,1-8$.

Salisbury, H. (1988). A Time of Change: A Reporter's Tale of Our Time. New York: Harper \& Row.

Shen, F., Ahern, L., \& Baker, M. (2014). Stories that count: Influence of news narratives on issue attitudes. Journalism \& Mass Communication Quarterly, 91(1), 98-117.

Stolberg, S. G., \& Babcock, S. (2015). Scenes of chaos in Baltimore as thousands protest Freddie Gray's Death. The New York Times. April 25.

Sundar, S. (1998). Effect of source attribution on perception of online news stories. Journalism \& Mass Communication Quarterly, 75(1), 55-68.

Van Dijk, T. A. (1985). Structure of news in the press. In T. A. Van Dijk (Eds.) Discourse and Communication: New Approaches to the Analysis of Mass Media Discourse and Communication, pp. 69-93. Berlin: Walter de Gruyter.

Van Dijk, T. A. (1988). News as Discourse. Hillsdale, NJ: Lawrence Erlbaum.

Van Dijk, T. A. (1991). Racism in the press. London: Routledge.

Van Dijk, T. A. (1992). Racism and argumentation: "Race riot" rhetoric in tabloid editorials. In F. H.van Eemeren (Eds.), Argumentation illuminated, pp. 242-259. Dordrecht: Foris.

Van Dijk, T. A. (1993). Elite Discourse and Racism. London: SAGE Publications.

Van Dijk, T. A. (1996). Opinions and ideologies in editorials Paper presented at the 4th International Symposium of Critical Discourse Analysis, Language, Social Life and Critical Thought (14-16 December, 1995), Athens.

Van Dijk, T. A. (1998). Opinions and ideologies in the press. In A. Bell, P. Garrett (Eds.), Approaches to Media Discourse, pp. 21-63. Oxford, UK: Blackwell.

Van Dijk, T. A. (2000). New(s) racism: A discourse analytical approach. In S. Cottle (Eds.), Ethnic minorities and the media, pp. 33-49. Milton Keynes, UK: Open University Press.

Van Dijk, T. A. (2006). Ideology and discourse analysis. Journal of Political Ideologies, $11(2), 115-140$.

Van Dijk, T. A. (2015). Critical discourse analysis. In D. Tannen, H. Hamilton, D. Schiffrin (Eds.), The Handbook of Discourse Analysis, pp. 466-485. Hoboken, NJ: John Wiley \& Son.

Van Krieken, K, Sanders, J., \& Hoeken, H. (2015). Viewpoint representation in journalistic crime narratives: An analysis of grammatical roles and referential expressions. Journal of Pragmatics, 88, 220-30.

Van Krieken, K., Sanders, J., \& Hoeken, H. (2016). Blended viewpoints, mediated witnesses: A cognitive linguistic approach to news narratives. In B. Dancygier, W-L. Lu, A. Verhagen (Eds.). Viewpoint and the Fabric of Meaning: Form and 
Use of Viewpoint Tools across Languages and Modalities, pp. 145-168. Berlin: Mouton de Gruyter.

Vestergaard, T. (2000a). From genre to sentence: The leading article and its linguistic realization. In F. Ungerer (Eds.), English media texts: Past and present, pp. 151175. Amsterdam: John Benjamins.

Vestergaard, T. (2000b). That's not news: Persuasive and expository genres in the press. In A. Trosberg (Eds.), Analyzing professional genres, pp. 97-113. Amsterdam: John Benjamins.

Victor, D., \& Mcphate, M. (2016). Critics of law enforcement embrace Facebook Live and other video tools. The New York Times.

Wahl-Jorgensen, K. (2013a). Subjectivity and story-telling in journalism. Journalism Studies, 14(3), 305-320.

Wahl-Jorgensen, K. (2013b). The strategic ritual of emotionality: A case study of Pulitzer Prize-winning articles. Journalism, 14(1), 129-145.

Wang, W. (2007). The notions of genre and micro-genre in contrastive rhetoric research: Newspaper commentaries on the events of September 11th. University of Sydney papers in TESOL, pp. 83-117.

Wegner, Y. (2015). Unrest will cost city \$20 million, officials estimate. The Baltimore Sun. May 26.

Weitzer, R. (2015). American policing under fire: Misconduct and reform. Society, 52(5), 475-480.

White, P. R. (2006). Evaluative semantics and ideological positioning in journalistic discourse: A new framework for analysis. In I. Lassen, J. Strunek, T. Vestergaard (Eds.). Mediating Ideology in Text and Image: Ten Critical Studies, pp. 37-67. Amsterdam/Philadelphia: John Benjamins.

Williams, H. E., Bowman, S. W., \& Jung, J. T. (2016). The limitations of government databases for analyzing fatal officer-involved shootings in the United States. Criminal Justice Policy Review, 1-22.

Wodak, R., \& Meyer, M. (2001). Methods of Critical Discourse Analysis. London: SAGE Publications.

Wolfe, S. E., \& Nix, J. (2016). The alleged "Ferguson Effect" and police willingness to engage in community partnership. Law and Human Behavior, 40(1), 1-10.

Zarza, S., \& Tan, H. (2016). Patterns of schematic structure and strategic features in newspaper editorials: A comparative study of American and Malaysian editorials. Discourse and Communication, 10(6), 635-657. 